Atualidades 



\title{
A família e o direito humano à alimentação adequada e saudável
}

\author{
ANA LYdia SAWAYA, ${ }^{I}$ ANNA MARIA PELIANO, ${ }^{I I}$ \\ MARIA PAULA DE ALBUQUERQUE, III \\ e SEMÍRAMIS MARTINS ÁlVARES DOMENE ${ }^{I V}$
}

\section{Introdução}

Q

UAL A IMPORTÂNCIA das famílias na promoção de uma alimentação saudável? Quais as implicações e dificuldades para se trabalhar o núcleo familiar como catalisador do direito humano à alimentação adequada? Qual a contribuição das famílias para o alcance de metas estabelecidas na Agenda 2030 de Desenvolvimento Sustentável? Foi para estimular a reflexão sobre questões dessa natureza que o Grupo de Nutrição e Pobreza do Instituto de Estudos Avancados da USP, em parceria com o Family Talks - associação vinculada à International Federation for Family Development, promoveu um encontro de especialistas, no formato de grupo focal, em setembro de 2018. Uma síntese das discussões, elaborada a partir da transcrição das intervenções dos participantes, é apresentada neste artigo.

Para avançar na compreensão do objeto, partiu-se da delimitação do conceito de que a família, conforme consta na Declaração Universal dos Direitos Humanos, representa o "núcleo natural e fundamental da sociedade", ${ }^{1}$ e deve receber "especial proteção do Estado" de acordo com a Constituição brasileira. ${ }^{2}$ Esse status é consequência de seu papel fundamental na formação das sociedades e culturas, bem como da constatação da universalidade dessa instituição. Mesmo em culturas bastante distintas, como Brasil e Japão, há mais semelhanças que diferenças entre as famílias.

É amplamente reconhecido que as tarefas levadas a cabo pelas famílias são essenciais para a sociedade e que suas responsabilidades se estendem dos cuidados e educação das crianças e adolescentes, aos cuidados com as pessoas idosas, com deficiência, doentes etc. Independentemente de sua configuração, a família é o primeiro espaço de convivência do ser humano e, portanto, fundamental para a formação das pessoas, especialmente das crianças nos primeiros 72 meses de vida, na chamada Primeira Infância, ${ }^{3}$ que representa o momento mais crítico para o desenvolvimento do ser humano. Ela é o primeiro e o mais importante mediador da criança com a sociedade. 
Entre as diversas tarefas sob a responsabilidade das famílias se destacam aquelas relacionadas aos cuidados com a saúde e a alimentação. É nesse ambiente que se inicia a formação do hábito alimentar das pessoas, sendo a principal influência na alimentação das crianças. Mais do que isso, as famílias são as maiores responsáveis pela transmissão da cultura alimentar, pois é nesse ambiente que as pessoas aprendem quais alimentos consumir e como prepará-los, a partir dos recursos disponíveis. Essa influência, positiva ou negativa, tende a persistir por toda a vida.

Em razão desse papel central no cuidado e na transmissão da cultura, das práticas e do hábito alimentar, é razoável considerar a família como lugar de destaque nas políticas públicas voltadas para a promoção da segurança alimentar. Não obstante esse reconhecimento, colocar a família no centro das políticas públicas de promoção de uma alimentação adequada e saudável ainda é um desafio para os gestores. No caso brasileiro, são vários os obstáculos a serem enfrentados, entre outros, a diversidade cultural e social do país que demanda a adoção de múltiplas e complexas estratégias; a fragmentação na condução das políticas públicas que dificulta a garantia da necessária intersetorialidade e complementaridade entre as ações do governo e da sociedade; as transformações na estrutura familiar que exigem flexibilidade e abertura para sucessivas mudanças e inovações; e a dimensão e dispersão, no território nacional, das famílias mais vulneráveis o que dificulta fazer chegar as políticas públicas ao nível dos domicílios.

\section{Metodologia}

O presente artigo apresenta os resultados de um debate realizado por meio da técnica de entrevista Focus Group (Krueger, 2002; Freitas et al., 1998). Essa técnica permite obter conhecimento de pesquisadores ou especialistas em determinado tema a partir de uma discussão objetiva em grupo. Tal discussão é conduzida por um moderador que propõe questões e tem a função de mediar as intervenções dos interlocutores. O conteúdo da entrevista é transcrito e analisado a fim de produzir um relatório, cujo objetivo é expor o teor das discussões e as principais conclusões dos participantes do encontro.

Para a condução do trabalho, a equipe organizadora promoveu um encontro entre pesquisadores, representantes de instituições da sociedade civil e de órgãos governamentais que atuam na promoção do direito humano à alimentação e nutrição adequadas, procurando refletir a pluralidade de experiências entre profissionais dedicados ao tema. Além disso, tendo em vista a intersetorialidade das questões envolvidas, buscou-se fomentar uma discussão interdisciplinar, com o envolvimento de profissionais de distintas áreas: nutricionistas, médicos e sociólogos, com diferentes trajetórias profissionais (na gestão pública, acadêmica ou no terceiro setor). A lista de participantes encontra-se no final deste trabalho.

Para facilitar a interação entre os participantes do encontro, foi elaborada uma questão, previamente enviada a todos com o intuito, seja de direcionar as intervenções aos objetivos propostos para o encontro, como de garantir alguma 
coerência entre as diferentes sugestões apresentadas. A pergunta elaborada foi a seguinte:

- Qual a relevância, as implicações e dificuldades para que a família possa ser catalisadora do Direito Humano à alimentação adequada?

A partir dessa questão iniciou-se a discussão pela identificação do grupo de famílias que deveriam ser alvo prioritário da atenção do grupo e das responsabilidades do Estado em assegurar a proteção social, por meio das políticas públicas. De modo específico, procurou-se debater o papel central da família - ou, de modo mais amplo, das relações familiares - na promoção de uma alimentação adequada, condição necessária para uma vida saudável; no processo de acesso e escolha dos alimentos; nas estratégias de educação nutricional; no estímulo a comer em companhia, considerando-o também como elemento de fortalecimento dos vínculos sociais; no desenvolvimento e prática das habilidades culinárias, com estímulo à responsabilidade compartilhada entre os integrantes do núcleo familiar; e no encontro de caminhos para atenuar os desafios decorrentes da falta crônica de tempo.

Ao considerar as contribuições das famílias para o alcance dos Objetivos de Desenvolvimento Sustentável (ODS) na elaboração do contexto, do escopo e dos objetivos dessa reflexão, assegurou-se o alinhamento das conclusões do encontro com as diretrizes já estabelecidas para o assunto em nível internacional e nacional. Vale ressaltar que o ODS em destaque foi o de número 2 - "Acabar com a fome, alcançar a segurança alimentar e melhoria da nutrição e promover a agricultura sustentável".

Os debates foram gravados e transcritos, e as informações registradas foram organizadas e classificadas, de modo a facilitar a apresentação e compreensão das reflexões do grupo. Os resultados apresentados a seguir destacam os principais tópicos tratados.

\section{Resultados}

\section{As vulnerabilidades das famílias de menor renda}

O ponto de partida da discussão do grupo focal foi identificar as condições de vida das famílias que deveriam ser alvo prioritário das políticas públicas. A análise centrou-se na população de menor renda, dada a enorme desigualdade social brasileira que leva a padrões de vida completamente diferentes nos distintos estratos sociais. Assim, os debates priorizaram a população mais vulnerável economicamente por ser a mais necessitada de políticas públicas de promoção de bem-estar social e de garantia de uma alimentação mais saudável.

Os membros das famílias brasileiras de menor renda geralmente possuem baixa escolaridade e, em decorrência, precária inserção no mercado de trabalho. Isso leva a uma constante instabilidade econômica, com várias consequências, dentre elas a própria dificuldade de manutenção das crianças na escola o que contribui para a manutenção do círculo de pobreza. Os baixos índices de con- 
clusão do Ensino Médio no país são um bom indicativo - em 2015, quatro em cada dez jovens de 19 anos não haviam concluído o Ensino Médio. ${ }^{4}$ Segundo pesquisa do Ipea, 23\% de jovens brasileiros entre 15 e 24 anos, na maioria mulheres de baixa renda, não estudam nem trabalham no Brasil. ${ }^{5}$ Dessa forma, a perspectiva de futuro para milhões de jovens é permanecer nessa situação de pobreza, com poucas possibilidades de melhorar efetivamente a sua qualidade de vida.

Os reflexos da instabilidade de renda se manifestam, também de forma contundente, nas condições de acesso a uma alimentação adequada tanto em termos quantitativos quanto qualitativos. Os últimos dados disponíveis sinalizam que aproximadamente um quarto do total de domicílios no país - algo correspondente a mais de 50 milhões de domicílios - ainda apresentava, em 2013, algum problema ou deficiência em termos de garantia de sua segurança alimentar. A crise econômica e a elevação dos níveis de desemprego dos anos recentes não permitem otimismo em relação à melhoria desse quadro.

À dificuldade de aquisição de alimentos saudáveis, alia-se a dificuldade para a compra de gás, prejudicando o preparo de refeições em casa e ampliando a tendência a se recorrer a alternativas frequentemente não saudáveis, como o uso de alimentos e bebidas ultraprocessados, ou seja, o consumo de alimentos prontos para o consumo como salgadinhos, biscoitos, refrigerantes, doces, balas, bolos, ou de muito fácil preparação como os embutidos. Os dados disponíveis da última Pesquisa de Orçamentos Familiares (POF) já apontavam que, de 2002 para 2008, houve crescimento da participação relativa de açúcares, alimentos processados e ultraprocessados (pães, embutidos, biscoitos, refrigerantes e refeições prontas) na dieta dos brasileiros: considerando a soma das médias de aquisição desses produtos por Unidade da Federação (UF), eles correspondiam, em 2002 , a $24 \%$ da aquisição de alimentos dos domicílios; em 2008, essa proporção subiu a 27,4\% (IPEA, 2019). Ademais, segundo o IBGE (2010), “a evolução do consumo de alimentos segundo os quintos da renda familiar indica aumento mais intenso na participação de alimentos processados prontos para consumo nos estratos de menor renda”.

A maciça propaganda realizada pelas indústrias produtoras desses alimentos e bebidas contribui para o agravamento da situação. Vale ressaltar aqui que um dos focos preferenciais das propagandas é a mensagem de que consumir o produto representa o caminho para a inclusão na sociedade de consumo, o que representa um grande apelo para a população de baixa renda.

Outra característica das famílias de menor renda é que, na maioria dos casos, a responsabilidade pelo cuidado da criança é concentrada na própria mãe (Arregui; Wanderley, 2011), muitas vezes em um arranjo familiar monoparental. Diversos estudos têm evidenciado que é nesse contexto em que geralmente se encontram os casos de desnutridos mais graves (Sawaya et al., 2011). Nesses casos, além da questão da renda, é necessário ter em conta outros problemas aí 
presentes, como o isolamento e a falta de suporte dessa mãe em seu contexto social. Esse isolamento diz respeito a uma rede social primária (familiar) pouco densa, implicando uma pobreza de recursos relacionais (Solymos, 2011; Soares et al., 2011).

Nos grandes centros, em particular, há ainda o agravante da falta crônica de tempo, que afeta pessoas de todas as classes sociais e que têm implicações diretas na qualidade de vida e de alimentação das pessoas. No caso das famílias com baixa renda, que geralmente vivem em periferias mais distantes, o tempo gasto em deslocamentos entre a residência e o local de trabalho pode ser superior a 4 horas diárias, a exemplo da cidade São Paulo. Essa realidade gera diversos problemas, a começar pelo cuidado de crianças ou dos idosos em situação de dependência, aliado à reconhecida escassez de equipamentos públicos como creches, escolas, serviços para idosos etc. Nesse contexto, alimentar-se adequadamente é um grande desafio, a começar pelo tempo necessário para adquirir alimentos saudáveis (indisponíveis especialmente na periferia dos centros urbanos) e prepará-los. Se, por um lado, há o reconhecimento da importância de se resgatar a cultura alimentar tradicional, por outro, é necessário ajudar as famílias a adotar estratégias de alimentação adequadas, o que é frequentemente desafiador.

\section{A familia nas politicas públicas}

A família é o espaço indispensável para a garantia da sobrevivência e da proteção integral dos filhos e demais membros, independentemente do arranjo familiar ou da forma como ela se estrutura. A inserção da família nas políticas públicas revela o reconhecimento de seu papel fundamental para alcance dos objetivos do desenvolvimento humano e social. Não obstante, ela não pode se responsabilizar sozinha por tal atribuição e, nesse sentido, o Estado deve assumir parte dessa responsabilidade com políticas de proteção social, por meio de programas e serviços sociais de qualidade e de caráter universal.

Vários programas governamentais recentes deram protagonismo à família: Bolsa Família, Estratégia Saúde da Família, programas de Agricultura Familiar, dentre outros. Mesmo com resultados positivos, gestores públicos destacam a necessidade, para uma maior efetividade, de se adaptar as políticas públicas à realidade encontrada nos domicílios, reflexo das mudanças sociais das últimas décadas que levaram a uma maior diversidade de arranjos familiares.

Assim, um desafio que se apresenta para os programas de apoio ao grupo familiar é o de não utilizar definições excludentes, que impeçam o acesso de várias pessoas e famílias a essas políticas. Esse tema é particularmente importante no contexto das famílias de baixa renda, que em muitos casos possuem relações mais fragilizadas e, portanto, uma variedade maior de arranjos familiares. Nesse sentido, é importante ressaltar a necessária cautela para pesquisas populacionais quando se utiliza a família como unidade de pesquisa. Uma alternativa prática, simples e não excludente é adotar o domić́lio como representante de uma uni- 
dade familiar; ou seja, todas as pessoas que moram juntas e dividem os bens e serviços constituem uma unidade familiar. Portanto, a sugestão é considerar "o grupo de pessoas que vive no domićlio (ou vizinhança) e compartilha as estratégias de sobrevivência" como essa unidade fundamental. No contexto da alimentação, isso pode incluir o compartilhamento do mesmo fogão e/ou refeição, da compra de alimentos, o que tende a gerar um hábito alimentar semelhante. Assim, recomenda-se como estratégica para a política pública, levar em conta tanto o domicílio como, de certa maneira, as relações interpessoais dos que ali habitam. Em outras palavras, trata-se de considerar como família o grupo de pessoas que ali reside.

Diante da diversidade de situações, questiona-se a viabilidade de desenhar políticas públicas para as famílias sem considerar também o território onde vivem, em seus diferentes matizes e situações. Nesse sentido, um cuidado a ser tomado no desenho das políticas públicas voltadas às famílias é que essas não devem ser abordadas de forma isolada, fora do contexto mais amplo em que vivem. Em relação à segurança alimentar, é evidente que fortes influências externas dificultam a alimentação saudável e adequada das famílias. Por exemplo: a crônica falta de tempo nas cidades; a instabilidade financeira; moradias precárias, com espaço insuficiente para a mesa e para refeições com "comida de verdade" e em horários adequados; assim como a dificuldade de se encontrar alimentos saudáveis nas periferias. Ou seja, a política pública precisa abordar essas outras realidades extrínsecas às famílias para ser efetiva.

A esse respeito foi ressaltada a necessidade do contato direto com as famílias e mencionadas algumas iniciativas da sociedade civil que conseguiram grande capilaridade e acesso às famílias mais vulneráveis a exemplo do método de Busca Ativa, adotado em caráter pioneiro, pelo Centro de Educação e Recuperação Nutricional (CREN), ainda no início dos anos 1990 (Martins; Solymos, 2011). O sucesso da iniciativa revela que há fundamento para se considerar uma abordagem que enriqueça a execução da política por meio de um acesso adequado e capilar no território, como é o método de Busca Ativa onde o agente executor da ação vai até a unidade familiar mais vulnerável e que necessita de atendimento. Tal estratégia permite o estabelecimento de abordagens adequadas às características locais e foi adotada pelo governo federal, por meio do Programa Bolsa Família. Na mesma linha foi desenhado o Programa de Agentes Comunitários de Saúde, que prevê a realização de visitas domiciliares e, mais recentemente, o Programa Criança Feliz, com uma cobertura ainda muito restrita (Ipea, 2019). ${ }^{6}$

Outro aspecto destacado é que, apesar de as políticas públicas atingirem hoje boa parte da população a que se destinam, grupos dispersos em regiões mais distantes ainda deparam com grande dificuldade de acesso às intervenções governamentais. Um exemplo é o acesso ao Bolsa Família por parte de indígenas aldeados no interior de regiões da Amazônia. Há casos registrados em que a família toda se desloca, fazendo longas e constantes viagens para acessar os 
benefícios. Isso gera várias instabilidades na vida daquelas pessoas, com impactos negativos na própria rotina alimentar. Portanto, há situações em que as políticas públicas precisam especializar-se para entregar, de maneira efetiva, um serviço de qualidade a determinados grupos populacionais, os quais não podem permanecer "invisíveis" nos dias atuais.

Nesse cenário complexo ressalta-se o grande potencial para uma atenção diferenciada às famílias, que pode ampliar o impacto das políticas públicas, desde que as intervenções sejam contextualizadas no território - com atenção à uma apropriada conceituação da família, para evitar exclusões. Uma estratégia para concretizar essa proposta é adotar uma abordagem relacional, onde as relações sociais presentes no território, sobretudo as das famílias, são alvo das políticas, conforme explicado a seguir.

\section{A abordagem relacional para recuperação e educação nutricional}

A qualidade das relações interpessoais é um importante aspecto a ser considerado na definição de intervenções destinadas às populações em condição de pobreza. A experiência de várias organizações da sociedade civil, dentre elas o CREN, ${ }^{7}$ indica que trabalhar as relações, por meio do desenho do mapa da rede social das pessoas de determinado território, é uma estratégia eficaz no combate e prevenção à subnutrição e obesidade infantil (Marques et al., 2010; Soares et al., 2011). Trata-se de identificar a rede de relações que envolvem a pessoa e mapear as interações positivas e negativas para sua alimentação (Souza et al., 2009). O desenvolvimento dessa técnica de abordagem social resultou da compreensão de que focalizar um ponto específico de vulnerabilidade e tentar resolvê-lo isoladamente é muito menos efetivo do que buscar reforçar a rede social da pessoa (Sawaya; Solymos, 2011). Ou seja, partiu-se da compreensão de que o problema principal está no contexto social frágil, e, por isso, intervenções em rede trazem impacto mais efetivo e duradouro. No caso específico da alimentação infantil, por exemplo, os distúrbios alimentares de uma criança são consequência dos alimentos que ela recebe nessa rede: família, vizinhos, família estendida, creche, escola etc. Portanto, intervenções que privilegiem o fortalecimento das interações positivas dessa rede, em paralelo a uma atuação nos pontos negativos, são estratégias mais eficazes para promover a boa nutrição.

A transformação da rede social envolve um processo de educação nutricional das pessoas e instituições envolvidas (escolas, por exemplo), mas deve começar pelos familiares. No caso das crianças, o primeiro ponto da rede será seu cuidador principal, quase sempre a mãe. Partindo de suas experiências de cuidado e alimentação recebidas quando criança, promove-se um resgate dessa "memória afetiva alimentar", ou seja, contextualiza-se a alimentação adequada em sua história pessoal. Dessa maneira, há uma valorização da "cultura alimentar" em que esse cuidador (a) está inserido - o que tem se revelado como um elemento importante de abordagens bem-sucedidas para recuperação e educação nutricional. 
No caso da subnutrição, sabe-se que há redução no número de internações hospitalares como consequência desse tipo de intervenção. Nesses casos, a intervenção na rede social da criança permite que essa se torne um elemento protetor, podendo prevenir novos casos e a reincidência dos distúrbios nutricionais. Por isso, estratégias que têm a família no centro das relações da pessoa atendida podem ser promissoras também para políticas públicas, contribuindo para ampliar a qualidade e o impacto dos programas governamentais.

Para fortalecer efetivamente essas redes sociais é necessário, no entanto, estender a atenção para os profissionais de equipamentos públicos, por exemplo as merendeiras, os diretores, e professores das escolas. ${ }^{8}$ Aqui a abordagem é a mesma: o resgate da memória afetiva alimentar e o reforço da motivação para a mudança de hábitos alimentares. Essa é, além do mais, uma maneira de trabalhar priorizando a motivação das pessoas envolvidas através de estímulos positivos, com a utilização do modelo motivacional de comportamento alimentar e de atividade física, como o modelo transteórico, por exemplo (Filgueiras; Sawaya, 2018). É importante ressaltar que a intervenção no contexto social e relacional da pessoa, aliada a outras abordagens é mais efetiva e possibilita, inclusive, uma redução de custos para o sistema de saúde com grande impacto em longo prazo.

\section{A atenção diferenciada à mulher}

Uma característica de muitas políticas públicas implementadas recentemente é a atenção especial à mulher. Nas políticas de agricultura familiar há um exemplo interessante: hoje, há linhas de crédito exclusivas para mulheres, e o próprio documento de identificação do agricultor familiar tem dupla titulação, para o homem e a mulher. Há situações mais conhecidas como as do Bolsa Família que, ao eleger as mulheres como receptoras preferenciais do benefício, contribuem para ampliar a sua autonomia econômica com reflexos positivos na sua posição em relação ao grupo familiar e à sociedade.

Essa prática de diferenciar o atendimento em razão de gênero está fundamentada, em primeiro lugar, na prevalência relevante de famílias monoparentais em contextos sociais de baixa renda, a maior parte chefiadas por mulheres. Evidentemente essa população é das mais necessitadas de atenção e apoio estatal. Além disso, as mulheres possuem um papel destacado na realização das tarefas de cuidado, sobretudo com crianças.

Por outro lado, é necessário que essas políticas consigam dar esse enfoque à mulher sem causar prejuízos às suas relações sociais. Isso poderia acontecer em situações nas quais a mulher, para acessar determinado benefício outorgado via política pública, necessitasse não ter um parceiro. ${ }^{9}$ Reconhece-se que as políticas vigentes, em geral, conseguem atender as mulheres sem criar tais dificuldades. ${ }^{10}$

Enfim, extrai-se que as famílias monoparentais enfrentam maior risco à sua segurança alimentar. Por isso, é fundamental dedicar maior atenção a esses grupos, sem criar estigmas e julgamentos precipitados, sobretudo em relação às mulheres. Além do mais, é importante rememorar o que foi mencionado an- 
teriormente sobre a falta de tempo para a mulher trabalhadora, acentuada pela ausência de alguém no domicílio com quem dividir as tarefas de cuidado. ${ }^{11}$

\section{O ambiente alimentar na promoção de uma alimentação saudável}

Programas mais recentes, desenvolvidos no Brasil, estão buscando reforçar a cultura alimentar das famílias e valorizar a diversidade alimentar do país. Como exemplo, destaca-se a publicação pelo Ministério da Saúde em colaboração com pesquisadores de várias universidades brasileiras do "Guia Alimentar para a População Brasileira" (Brasil, 2014). Esse documento destaca a importância de ambientes alimentares em que se cozinhe e alimente adequadamente as pessoas, com possibilidade de transmissão das habilidades culinárias - sem dúvida as famílias propiciam locais privilegiados para isso. Dessa forma, a publicação ressalta o papel insubstituível da família na formação do hábito alimentar da pessoa, cuja consequência é o reforço da própria cultura alimentar, transmitida entre as gerações. Além disso, uma das recomendações é o comer em companhia, inclusive de familiares, e não de forma isolada ou em frente à televisão, como forma de “criar e desenvolver relações entre pessoas". O núcleo familiar, portanto, não só propicia a ocasião da refeição em companhia, como beneficia-se desse momento para reforçar as relações entre seus membros.

O Guia tem sido considerado, em nível mundial, como o mais desenvolvido e atualizado para promoção de alimentação saudável e vem sendo seguido em outros países. ${ }^{12}$

Vale ressaltar que, apesar do direcionamento correto proposto nas políticas públicas (sobretudo no Guia), na prática muitas famílias encontram dificuldades para a sua adoção. As causas já foram relatadas na discussão sobre a situação das famílias brasileiras de baixa renda. Seja como for, são várias as dificuldades, por exemplo, para a refeição domiciliar em companhia. Em decorrência dessa situação questiona-se, por um lado, se as recomendações do Guia Alimentar são factíveis para a realidade de muitas famílias e cobra-se, por outro, a necessidade de favorecer leis e condições de trabalho que protejam a mulher no cuidado dos filhos pequenos.

Mesmo sendo um desafio ainda por resolver, é clara a necessidade de apoiar as famílias na adoção de estratégias para melhorar o ambiente alimentar. Uma abordagem mais ousada é reconhecer que, em muitos contextos, a refeição no domicílio é impraticável e, portanto, cabe desenvolver ambientes comunitários nos quais haja refeições adequadas e que permitam o envolvimento das famílias no preparo dos alimentos - garantindo a transmissão das habilidades culinárias. Por exemplo, pensar em restaurantes populares ou outros equipamentos públicos que tenham essas características. Alternativa interessante, com o intuito de promover o acesso a uma alimentação saudável, é a realização de compras comunitárias de alimentos. Em suma, mesmo que a refeição no domicílio não seja possível, refeições comunitárias propiciadas por políticas públicas poderiam, além de assegurar a alimentação adequada, propiciar ocasião para a transmissão intergeracional de saberes, essencial para a manutenção da cultura alimentar. 
Nesse campo é importante destacar que muitas organizações da sociedade civil conseguem especializar-se e entregar serviços de qualidade, que podem servir de referência para políticas públicas federais. Um caso concreto é a eficiência com que o CREN consegue reforçar as relações interpessoais no território, melhorando a saúde e alimentação daquelas pessoas por meio da abordagem de rede social. Nessa abordagem o ponto de partida sempre é a existência de uma necessidade, individual ou coletiva. Atua-se com a pessoa que traz a demanda e com as pessoas que são significativas para a solução do problema, como família, amigos, colegas de trabalho, pessoas que estão disponíveis ou que consentem estar relacionados com a solução do problema. Portanto, as condições para a realização do trabalho são o consenso e a disponibilidade das pessoas. Quando se intervém em uma rede, é importante ter atenção para o discurso coletivo. Ele permitirá avaliar a possibilidade de estabelecer alianças, verificar a proximidade ou distância afetiva entre as pessoas em atendimento que compõem a rede e saber se a proximidade é suficiente para poder contar com certas pessoas na solução do problema ou se, sendo distante será preciso um trabalho anterior de sensibilização e aproximação. $\mathrm{Na}$ abordagem de rede está incluída a atuação com redes secundárias, que permite estabelecer uma rede de serviços e integrar as diversas intervenções realizadas pelas instituições, evitando duplicidade de atendimentos para uma mesma pessoa ou família.

Assim, é fundamental resgatar a concepção de parceria entre sociedade civil e Estado para a execução das políticas públicas. Não se trata apenas de garantir à sociedade o direito de atuar em contextos em que o serviço público não chega, mas de trabalhar em conjunto com a sociedade civil especializada e suas organizações buscando promover a complementaridade das ações, o intercâmbio de experiências e saberes, a participação social, a democratização das intervenções governamentais, e a melhoria da qualidade da intervenção.

Por fim, é necessário possibilitar uma maior flexibilidade na ponta para os responsáveis pela operacionalização da política pública, para adaptar-se às idiossincrasias dos diferentes territórios. Só assim será possível realmente adaptar-se às particularidades de cada contexto e efetivamente atender as populações que ainda estão desassistidas.

\section{A importância da formação profissional}

A formação dos profissionais de saúde com olhar para as famílias é uma das maneiras para melhorar o impacto nas políticas públicas. Um exemplo que ilustra bem essa necessidade de processos de educação permanente em saúde é o tema da promoção do aleitamento materno. Atualmente o Brasil tem diversos programas para incentivar a amamentação dentre eles a iniciativa Hospital Amigo da Criança. Tal iniciativa conta com os Dez Passos para o Sucesso do Aleitamento Materno, um sumário das orientações para as maternidades promoverem, protegerem e apoiarem o aleitamento materno. 
Dentro dessas orientações o passo 2 aponta para a necessidade de capacitar toda a equipe de cuidados de saúde nas práticas necessárias para implementar essa política, enquanto o passo 6 orienta não oferecer ao recém-nascido nenhum outro alimento ou bebida além do leite materno, a não ser que tenha indicação clínica. No entanto, mesmo com a existência de um grande número de documentos, guidelines e consensos como esse, observa-se ainda uma prática nas maternidades, por parte dos profissionais de saúde, de oferecer líquidos, muitas vezes antes mesmo do leite materno, como água, chá, água com açúcar, glicose, soro e outros tipos de leite e fórmulas infantis sem uma indicação clínica adequada para um grande número de recém-nascidos. Essa prática resulta em iatrogênica interrupção do aleitamento materno exclusivo, reduz a prevalência de aleitamento materno na primeira hora de vida, ambos indicadores de segurança alimentar, e expõe a díade mãe e filho à maior risco nutricional (Sociedade..., 2017).

Além disso, considerando as dificuldades já relatadas para a refeição em domicílio, muitas vezes as refeições disponíveis nos equipamentos públicos podem ser a principal no dia de muitas pessoas - por exemplo, a merenda escolar para escolares de família com baixa renda. Logo, as merendeiras têm um papel destacado na promoção da segurança alimentar. Nesse sentido, a atenção às famílias precisa ser complementada pela atenção aos profissionais das instituições nas quais são ofertados serviços aos seus diversos membros, dado o papel decisivo que possuem na garantia de alimentação adequada e saudável.

Um projeto de formação de profissionais realizado em São Paulo por uma organização do terceiro setor ${ }^{13} \mathrm{em}$ parceria com a prefeitura da cidade, intitulado "Cuidar de quem cuida", pode ser uma referência interessante. Em um primeiro momento, trata-se de trazer ao profissional da ponta um senso de propósito para seu trabalho, de modo a exercer criticamente seu papel e deixar de ser um mero executor. Há relatos da transformação causada, por exemplo, em grupos de aleitamento materno, que passam a funcionar adequadamente quando esses profissionais estão imbuídos de propósito.

No contexto da alimentação, os profissionais de saúde enfrentam as mesmas dificuldades que a população em geral: restrições de tempo, influência negativa da propaganda, dentre outros. Por isso, nesse processo de formação, é necessário que o tema da alimentação saudável e adequada faça sentido para as pessoas. Para tanto, enfatiza-se novamente a importância de se apelar à memória afetiva dos profissionais, resgatando as experiências alimentares que tiveram em suas vidas, o que também contribui para o fortalecimento das culturas alimentares. A partir desse resgate, o profissional pode encontrar com muito mais facilidade o propósito de sua missão de cuidar dos outros, pois essas atividades passam a estar conectadas com sua própria história.

Vale ressaltar que a abordagem do "cuidar de quem cuida" é uma forma de fortalecer e potencializar os laços positivos nas redes em que as pessoas, e 
consequentemente as famílias, estão inseridas. Como já destacado, no caso das políticas de alimentação, um resultado esperado dessa abordagem é a redução do número de crianças com subnutrição e obesidade, com consequente redução nos custos com saúde. Sem dúvida, essa personalização do atendimento aos profissionais de saúde, aliada a maior atenção às relações interpessoais, pode ser um importante passo para novas políticas públicas (ou evolução para as atuais) e, especificamente, para a formação profissional - inicial e permanente - dos agentes de saúde e demais prestadores de serviços em equipamentos que oferecem algum tipo de alimentação.

Nesse aspecto, o Guia Alimentar para crianças menores de dois anos (a ser publicado) traz inovações em relação ao Guia já disponível. A principal delas é a atenção devida à pessoa que prepara o alimento: a necessidade de formação dessa pessoa; o cuidado com a situação ambiental, por exemplo, se há mesa no domicílio; local adequado para armazenamento do alimento. Trata-se de um importante avanço cujas recomendações trarão benefícios também aos profissionais dos equipamentos públicos, impactando sua formação.

Atenção particular merece o Agente Comunitário de Saúde. Esse profissional é uma "potência" dentro do território, ou seja, a figura-chave para efetivamente articular a entrega do serviço público para as famílias. Na prática, isso ocorre porque ele tem acesso aos domicílios e conhece as pessoas. Uma dificuldade existente é a baixa inserção desse profissional nas equipes de saúde, que são muito centralizadas na figura do médico. Assim, fazer que a política pública - e suas equipes - mude o olhar sobre o Agente, deve ocasionar um impacto positivo na qualidade dos serviços oferecidos. Além disso, o Agente pode facilitar a compreensão do "trabalhar pelo bem comum", contrapondo-se a uma visão muito especializada do atendimento em saúde, própria dos profissionais da área. Por fim, esse olhar precisa ser estendido para as políticas promovidas no meio rural.

Outro aspecto importante é o papel do SUS como ordenador da formação do profissional de saúde. A construção conjunta - serviço e Universidade - de estratégias de aprendizagem nos territórios, pode potencializar uma maior integração das necessidades da sociedade à formação técnica, por meio da extensão universitária. Um desafio correlato é fidelizar esses profissionais na rede pública e no território.

Em resumo, uma nova atenção à formação dos profissionais, especialmente de saúde, capacitando-os para esse olhar personalizado, pode ser um grande impulso para ampliar a prevenção de distúrbios alimentares e melhorar os resultados das políticas públicas. Também pode propiciar um novo olhar para a família no território, passo importante para ampliar o alcance das políticas destinadas aos grupos mais vulneráveis. Ademais, a formação dos profissionais envolvidos em políticas públicas dentro dessa visão humanizadora, integral, está alinhada com o proposto pelos Objetivos de Desenvolvimento Sustentável (ODS). ${ }^{14}$ 


\section{A influência da propaganda nos hábitos alimentares}

Um ponto de consenso entre o grupo focal foi a importância de desenvolver políticas públicas que visem à informação do consumidor e das famílias, por meio da regulação na propaganda e no mercado alimentício. É notório que, em muitos casos, a publicidade de alimentos nutricionalmente inadequados invade a privacidade das famílias e influencia negativamente sua tomada de decisão. Por exemplo, relatou-se o desenvolvimento de produtos alimentícios para bebês de uma grande multinacional, cuja propaganda contribuiu para o desmame precoce, para o afastamento das mães e seus filhos por meio do consumo de leite processado e papinhas pré-fabricadas. Uma das técnicas dessa propaganda foi mostrar, de forma progressiva, o produto junto com o bebê, independente da mãe, induzindo à percepção que a alimentação da criança, mesmo muito pequena, não precisa da mãe, e essa pode cuidar de seus outros afazeres, sem se preocupar diretamente com o bebê. Muitas pesquisas científicas demonstraram que, na prática, propagandas como essa tiveram o efeito de introduzir as mamadeiras na alimentação dos pequenos, o que contribuiu para a redução do aleitamento materno, com consequente aumento da prevalência de doenças infecciosas e de quadros alérgicos, além do aumento da massa de gordura corporal, obesidade e diabetes no futuro, com consequências muito nefastas para a saúde em longo prazo (Kassahara; Sarti, 2018).

Mesmo para adultos, os alimentos inadequados - como os ultraprocessados - podem surgir como alternativa devido à influência da propaganda. $\mathrm{O}$ impacto da publicidade na liberdade das famílias é relevante sobretudo naquelas cujos membros possuem menor escolaridade. Na prática, a propaganda dificulta o acesso a informações relevantes para essas decisões, como a qualidade nutricional do alimento, ao enfatizar outros aspectos. No contexto da sociedade de consumo essa influência é ainda maior, reduzindo o espaço de reflexão e, em certo sentido, a liberdade das famílias.

Trata-se, portanto, de um desafio para o gestor público: proteger as famílias dessas influências negativas resguardando, ao mesmo tempo, sua liberdade de escolha para a alimentação saudável. Esse equilíbrio pode ser alcançado por meio de ações de regulação e informação, na opinião dos debatedores. $\mathrm{O}$ resultado esperado com essas intervenções é influenciar os hábitos de consumo das pessoas.

Nessa direção, há casos de sucesso recentes no Brasil. Em primeiro lugar, a introdução dos medicamentos genéricos no mercado: chegaram a ser vistos com desconfiança, mas hoje são amplamente consumidos. Depois, a regulação do consumo do tabaco, que teve efeitos práticos positivos no hábito das pessoas. Pode-se mencionar, também, a utilização do cinto de segurança: incomum há 20 anos, hoje, com o advento do Código de Trânsito, tornou-se um hábito dos brasileiros.

Com relação à informação adequada no rótulo de alimentos ultraprocessados, existe experiência bem-sucedida do Chile. Assim, espera-se que garan- 
tindo informação adequada, estimulando a mudança de hábitos não saudáveis e regulando o consumo de ultraprocessados - ou outros alimentos que causem malefícios à saúde da população, ao lado de ações no território para ampliar o acesso a alimentos saudáveis e para promover estratégias para seu preparo - seja possível ampliar o impacto das políticas de alimentação.

\section{Conclusões}

Nos debates realizados sobre o tema central do encontro - a relevância, as implicações e dificuldades para que a família possa ser catalisadora do Direito Humano à alimentação adequada - destacou-se o reconhecimento da importância do papel da família, independentemente da forma como ela se estrutura, no cuidado e na transmissão da cultura, das práticas e do hábito alimentar. Indispensável, portanto, atribuir-lhe um lugar de destaque nas políticas públicas voltadas para a promoção da segurança alimentar.

Ademais, dadas as desigualdades sociais verificadas no país, enfatizou-se a necessidade de conferir uma atenção especial às famílias de menor renda que se defrontam com grandes dificuldades para garantir uma alimentação saudável. Para isso concorrem, dentre outros, a instabilidade financeira que restringe o acesso aos alimentos na quantidade necessária e na qualidade recomendada; a falta de um ambiente alimentar adequado devido às condições precárias das moradias, com espaço insuficiente para a mesa e para elaboração de refeições com "comida de verdade", em horários recomendados; a falta de tempo crônica nas cidades aliada à dificuldade para a aquisição de alimentos saudáveis nas periferias; e as mudanças de hábitos alimentares decorrentes da maciça propaganda de bebidas e alimentos ultraprocessados, nutricionalmente prejudiciais à saúde. Como agravante, é nesse grupo da população que se encontra uma grande presença de famílias monoparentais, onde cabe especialmente às mães, muitas vezes isoladas de seu contexto social, a tarefa exclusiva de cuidar dos seus dependentes. Esse isolamento diz respeito a uma rede social primária (familiar) pouco densa, implicando uma pobreza de recursos relacionais com reflexos negativos na qualidade dos cuidados prestados. Diversos estudos têm evidenciado que é nesse ambiente que geralmente encontram-se os casos de subnutridos mais graves.

Diante desse quadro multifacetado de problemas, fica evidente a complexidade e os desafios que se apresentam para o desenho e a implementação das políticas públicas de alimentação. Romper o círculo vicioso da pobreza, fazer chegar políticas adequadas aos diferentes territórios e contextos em que vivem as famílias brasileiras, garantir o atendimento nas regiões mais distantes e superar as fragilidades das redes de proteção local foram destacadas entre as principais preocupações que devem orientar os caminhos a serem seguidos.

Sem a pretensão de esgotar os debates sobre o tema, o grupo identificou diversas ações a serem adotadas na busca da garantia do direito humano a uma alimentação adequada. De início foi enfatizada a necessidade de garantir o acesso direto às famílias, com a adoção de estratégias como a da Busca Ativa 
em que o agente executor dessa ação vai até a unidade familiar que necessita de atendimento. Os resultados positivos obtidos em programas dessa natureza desenvolvidos por organizações da sociedade civil (a exemplo do CREN) e pelo governo (Bolsa Família) reforçam a viabilidade de tal iniciativa. No âmbito da atenção às famílias, recomendou-se ainda um tratamento diferenciado à mulher, dado o seu papel fundamental na realização das tarefas de cuidado, sobretudo das crianças, e a prevalência relevante de famílias monoparentais, chefiadas por mulheres, em contextos sociais de baixa renda.

Foi ressaltado nos debates, que intervenções que atentam para o contexto social e relacional da pessoa, têm se mostrado especialmente efetivas. Assim, a "abordagem relacional", em que as relações sociais presentes no território são vistas como essenciais para o enfrentamento dos problemas locais, foi altamente recomendada. A proposta é evitar intervenções pontuais e isoladas para superar as vulnerabilidades das pessoas e privilegiar iniciativas que buscam identificar, fortalecer e envolver a rede de relações sociais que reconhecidamente podem contribuir para a melhoria da qualidade de vida e de alimentação das famílias.

A importância do fortalecimento das relações interpessoais também se estende para a promoção de um ambiente alimentar adequado. Para tanto, o grupo corroborou a recomendação contida no Guia Alimentar para a População Brasileira, publicado pelo Ministério da Saúde, de estimular as pessoas a comerem em companhia, o que contribui para a formação e transmissão intergeracional de saberes, essencial para a manutenção da cultura alimentar. Em casos em que a refeição no domicílio é impraticável a proposta foi na direção de estimular alternativas que possam trazer benefícios semelhantes, a exemplo de restaurantes populares ou outros equipamentos públicos que propiciem a prática de refeições ou mesmo de compras comunitárias.

A questão da educação nutricional, tanto dos cuidadores quanto dos profissionais das instituições envolvidas (merendeiras, por exemplo), foi outro ponto bastante enfatizado. Nesse campo o destaque foi para a adoção de metodologias que busquem valorizar a "memória afetiva alimentar", a partir do resgate das experiências com a alimentação recebida quando criança. Essa estratégia de valorização da "cultura alimentar", em que os cuidadores estão inseridos, tem se revelado bem-sucedida, não só para aprimorar o padrão da educação alimentar, mas também para motivar e engajar os profissionais na sua missão de cuidar da alimentação dos outros, segundo depoimentos dos especialistas.

Ao final dos debates, o grupo se debruçou sobre a questão do impacto perverso, das propagandas maciças de bebidas e alimentos nutricionalmente inadequados, nos hábitos alimentares da família. Refletiu-se sobre a importância de desenvolver estratégias voltadas para informar melhor o consumidor, por meio da regulação da propaganda e do mercado alimentício. Em resumo, o objetivo dessas intervenções deve ser o de proteger as famílias das influências negativas das propagandas resguardando, ao mesmo tempo, sua liberdade de escolha. 
Pelos diversos ângulos analisados, ficou mais uma vez evidenciado o papel fundamental das famílias no desenvolvimento da sociedade. Não por acaso, a ONU reconhece que políticas públicas voltadas à família possuem o potencial de acelerar o alcance de várias metas da Agenda 2030 para o Desenvolvimento Sustentável. Nesse encontro, promovido pelo Grupo de Nutrição e Pobreza do IEA, foi possível identificar que a partir de uma perspectiva da família as políticas públicas podem estabelecer uma conexão direta com os objetivos que tratam do combate à pobreza (ODS 1), da promoção da segurança alimentar (ODS 2), de uma vida saudável (ODS 3), da educação de qualidade (ODS 4), da igualdade de gênero (ODS 5), da redução das desigualdades (ODS 10) e de um padrão de consumo sustentável (ODS 12). Isso reflete a amplitude dos temas debatidos e a riqueza dos resultados apresentados.

\section{Notas}

1 Cf. Declaração Universal dos Direitos Humanos, art. $16 \$ 3$.

2 Cf. Constituição Federal, art. 226.

3 Mais informações podem ser encontradas neste endereço do site do Unicef: Disponível em: <https://www.unicef.org/early-childhood-development>.

4 Disponível em: <https://oglobo.globo.com/sociedade/educacao/pesquisa-revela-que-415-dos-jovens-de-19-anos-nao-concluiram-ensino-medio-21162505>.

5 Para mais informações: <http://agenciabrasil.ebc.com.br/geral/noticia/2018-12/ ipea-23-dos-jovens-brasileiros-nao-trabalham-e-nem-estudam $>$.

6 "O programa consiste em visitas domiciliares por profissionais da área de assistência social com o objetivo fortalecer os vínculos familiares entre cuidador e criança a fim de estimular o desenvolvimento infantil. Além disso, pretende identificar vulnerabilidades para encaminhar ações por meio de uma rede pública intersetorial da assistência social, secretarias municipais de educação e serviços municipais de saúde, dentre outros. Até abril de 2018, o programa acompanhou um total de 275 mil crianças e 37 mil gestantes em 2.044 municípios (MDS, 2018).”

7 Disponível em: <http://www.cren.org.br>.

8 É relevante destacar dados de um estudo realizado com crianças no município de São Paulo, o qual revelou que $75 \%$ delas estão recebendo alimentação inadequada nas escolas.

$9 \mathrm{Na}$ discussão foi mencionado o risco de se restringir o acesso a determinados benefícios a ausência de um companheiro. Poderia ocorrer situação em que, com o marido desempregado em casa, fosse mais conveniente para a mulher interromper esta relação para poder acessar o benefício. Ou seja, um incentivo para a ruptura deste vínculo.

10 Merece também ser observado os riscos da ausência de um olhar diferenciado para a perspectiva da mulher, conforme observação feita ao desenho do Programa Criança Feliz: “o Programa deveria, a partir de um diagnóstico da situação da criança e da família, encaminhar o atendimento de suas necessidades aos serviços competentes por meio de ação intersetorial, tarefa esta que ainda não se iniciou. Assim, o programa objetiva trazer qualidade à interação entre cuidadores e filhos no domicílio, mas pa- 
rece não reconhecer a realidade de imensa sobrecarga da dupla jornada feminina, em especial das mulheres em pobreza. Sugere-se, desta forma, que o Programa desenvolva mecanismos para ampliar a participação masculina no cuidado e nos afazeres domésticos” (Ipea, 2019).

11 Do ponto de vista da segurança alimentar, a companhia da criança com a mãe, garantida pela licença maternidade, é fundamental para, além do aleitamento materno, possibilitar formação do hábito alimentar - mais um motivo para avaliar se os tempos de licença disponíveis hoje são suficientes. Além disso, é necessário ter em conta estudos consistentes sobre a importância de licença paternidade para diminuir as desigualdades de gênero.

12 Disponível em: <https://www.cbc.ca/natureofthings/features/brazils-revolutionary-new-food-guide-focuses-on-how-food-is-mades.

13 CREN - Centro de Recuperação e Educação Nutricional

14 A meta 4.7 dos ODS 4 estabelece: “Até 2030, garantir que todos os alunos adquiram conhecimentos e habilidades necessárias para promover o desenvolvimento sustentável, inclusive, entre outros, por meio da educação para o desenvolvimento sustentável e estilos de vida sustentáveis, direitos humanos, igualdade de gênero, promoção de uma cultura de paz e não violência, cidadania global e valorização da diversidade cultural e da contribuição da cultura para o desenvolvimento sustentável".

\section{Referências}

ARREGUI, C. C.; WANDERLEY, M. B. Gestão pública e pobreza: um estudo de famílias chefiadas por mulheres. In: SAWAYA, A. L.; PELIANO, A.; SOLYMOS, G. M. B.; WANDERLEY, M. B.; DOMENE, S. M. A. (Org.) Desnutrição, pobreza e sofrimento psíquico. São Paulo: Edusp, 2011. cap.9.

BRASIL. Ministério da Saúde. Secretaria de Atenção à Saúde. Departamento de Atenção Básica. Guia alimentar para a população brasileira / Ministério da Saúde, Secretaria de Atenção à Saúde, Departamento de Atenção Básica. 2.ed. Brasília: Ministério da Saúde, 2014.

FILGUEIRAS, A. R.; SAWAYA, A. L. Multidisciplinary and motivational intervention for the treatment of low income Brazilian obese adolescents. Revista Paulista de Pediatria, São Paulo, v.36, n.2, p.186-91, 2018.

FREITAS, H.; OLIVEIRA, M.; JENKINS, M.; POPJOY, O. The focus group, a qualitative research method. ISRC, Merrick School of Business, University of Baltimore (MD, EUA), Working Paper N.010298, 1998.

IBGE. Pesquisa de Orçamentos Familiares 2008-2009. Avaliação nutricional da disponibilidade domiciliar de alimentos no Brasil. Rio de Janeiro, 2010. Disponível em: <https://biblioteca.ibge.gov.br/visualizacao/livros/liv47310.pdf>.

IPEA. ODS 2. Fome Zero e Agricultura Sustentável. Cadernos ODS, Ipea, Brasília, 2019. Coord. Alexandre Valadares e Fábio Alves. Disponível em: <http://www.ipea. gov.br/portal/images/stories/PDFs/livros/livros/190625_cadernos_ODS_objetivo_2.pdf>.

IPEA. ODS 5. Igualdade de gênero. Cadernos ODS, Ipea, Brasília, 2019. Coord. Joana Mostafa, Marcela Rezende e Natália Fontoura. No prelo. 
KASSAHARA, A.; SARTI, F. M. Marketing of food and beverage in Brazil: scientific literature review on regulation and self-regulation of advertisements. Interface, Botucatu, v.22, n.65, p.589-602, 2018.

KRUEGER, R. Designing and Conducting Focus Group Interviews. S. 1.: University of Minnesota, 2002.

MARQUES, E. S. et al. Rede social: desvendando a teia de relações interpessoais da nutriz. Revista de Saúde Coletiva, Rio de Janeiro, v.20, n.1, p.261-81, 2010.

MARTINS, P. A.; SOLYMOS, G. M. B. Avaliação do estado nutricional de crianças pobres: o método da busca ativa. In: SAWAYA, A. L.; PELIANO, A.; SOLYMOS, G. M. B.; WANDERLEY, M. B.; DOMENE, S. M. A. (Org.) Desnutriçãa, pobreza e sofrimento psíquico. São Paulo: Edusp, 2011. cap.5.

MDS. SUAS e o Programa Criança Feliz. Brasilia, 2018. Disponível em: <https:// www.mds.gov.br/webarquivos/publicacao/assistencia_social/Cadernos/Interacao_ Suas_CF.pdf>.

MYNARSKA, M.; RIEDERER, B.; JASCHINSKI, I.; KRIVANEK, D.; NEYER, G.; OLÁH, L. Vulnerability of families with children: Major risks, future challenges and policy recommendations. In: Families and Societies Project, Working Paper 49, 2015.

SAWAYA, A. L.; BENEDITO-SILVA, A. A.; LESSA, S. S.; FLORÊNCIO, T. M. M. T. Perfil da pobreza e desnutrição de favelas de Maceió. In: SAWAYA, A. L.; PELIANO, A.; SOLYMOS, G. M. B.; WANDERLEY, M. B.; DOMENE, S. M. A. (Org.) Desnutrição, pobreza e sofrimento psíquico. São Paulo: Edusp, 2011. cap.6.

SAWAYA, A. L.; SOLYMOS, G. M. B. A aventura do conhecimento. In: SAWAYA, A. L.; PELIANO, A.; SOlYMOS, G. M. B.; WANDERLEY, M. B.; DOMENE, S. M. A. (Org.) Desnutrição, pobreza e sofrimento psíquico. São Paulo: Edusp, 2011. cap.1.

SOARES, M. L. P. V.; DO NASCIMENTO, C. R.; WANDERLEY, M. B. A construção de uma metodologia de intervenção social. A experiência do Serviço Social no Centro de Recuperação e Educação Nutricional em São Paulo. In: SAWAYA, A. L.; PELIANO, A.; SOLYMOS, G. M. B.; WANDERLEY, M. B.; DOMENE, S. M. A. (Org.) Desnutrição, pobreza e sofrimento psíquico. São Paulo: Edusp, 2011. cap.8.

SOCIEDADE BRASILEIRA DE PEDIATRIA. Uso e abuso de fórmula infantil na maternidade em recém-nascidos sadios a termo. Departamento Científico de Aleitamento Materno. Documento Científico, n.5, agosto 2017.

SOLYMOS, G. M. B. Sofrimento, pobreza e desnutrição. In: SAWAYA, A. L.; PELIANO, A.; SOlYMOS, G. M. B.; WANDERLEY, M. B.; DOMENE, S. M. A. (Org.) Desnutrição, pobreza e sofrimento psíquico. São Paulo: Edusp, 2011. cap.4.

SOUZA, M. H. et al. A utilização do Referencial Metodológico de Rede Social na Assistência de Enfermagem a Mulheres que Amamentam. Revista Latino-americana de Enfermagem, Ribeirão Preto, v.17, n.3, 2009. Disponível em: <http://www.scielo.br/ $\mathrm{pdf} / \mathrm{rlae} / \mathrm{v} 17 \mathrm{n} 3 / \mathrm{pt} \_12 . \mathrm{pdf}>$.

THE UPDATE TEAM. Brazilian dietary guidelines. At last! Guidelines based on food and meals! World Nutrition, Jakarta, v.5, n.12, p.1050-1, 2014. 


\section{Lista de participantes do Grupo Focal:}

Ana Lydia Sawaya (Unifesp e IEA-USP), Anna Maria Peliano (IPEA e IEA-USP), Lilian dos Santos Rahal (Ministério do Desenvolvimento Social), Maria Paula Albuquerque (CREN e IEA-USP), Mariana Pinheiro (Ministério do Desenvolvimento Social), Michele Lessa (Ministério da Saúde), Sandra Maria Sawaya (USP e IEA-USP), Semiramis Martins Álvares Domene (Unifesp e IEA-USP), Denise Chaer (Novos Urbanos) e Rodolfo Canônico (FamilyTalks).

RESUMO - Este artigo tem por objetivo contribuir para a reflexão sobre a importância, as implicações e as dificuldades para trabalhar com o núcleo familiar como elemento catalisador do Direito Humano à alimentação adequada. O levantamento das informações foi realizado por meio da técnica de entrevista Focus Group e contou com a participação de profissionais de distintas áreas, como nutricionistas, médicos e sociólogos, com diferentes trajetórias profissionais na gestão pública, acadêmica ou no terceiro setor. Dos resultados extraídos dos debates, destacam-se as informações sobre a relevância da família, independentemente da forma como ela se estrutura, no cuidado e na transmissão da cultura, das práticas e do hábito alimentar. Portanto, é necessário atribuir-lhe um lugar de destaque nas políticas públicas de segurança alimentar. Face às desigualdades sociais verificadas no país, enfatizou-se a necessidade de conferir uma atenção especial e abrangente às famílias de menor renda, cuidando da complexidade dos problemas que afetam esse grupo da população. O texto apresenta a percepção do grupo focal sobre diversas estratégias e iniciativas a serem adotadas para a promoção do direito universal à alimentação adequada, a exemplo da Busca Ativa, da abordagem relacional, da educação nutricional diferenciada para cuidadores e profissionais da área, da informação maciça aos consumidores e da regulação da propaganda e do mercado alimentício.

PALAVRAS-CHAVES: Ambiente alimentar, Papel da família, Educação nutricional, Propaganda de alimentos, Política pública.

ABSTRACT - This article aims to contribute to the reflection on the importance, implications and difficulties of working with the family as a central element to attain the Human Right of adequate food. The survey was conducted with focus group interviews and was attended by professionals from different areas, such as dietitians, physicians and sociologists, with different professional backgrounds in public, academic or third sector management. The reports extracted from the debates highlight information on the extreme relevance of the family, regardless of its format, to the preservation and transmission of eating culture, practices and habits. Therefore, the family must take on a prominent role in public food security policies. Given the social inequalities in Brazil, the need to pay special and comprehensive attention to lower income families was emphasized, as well as the complexity of the problems that affect this stratum of the population. This text presents the focus group's perception of various strategies and initiatives to be adopted to promote the universal right of adequate food, such as active search, relational approach, differentiated nutritional education for caregivers and health professionals, massive information for consumers and regulation of advertising and food market. 
KEYWORDS: Food environment, Role of family, Nutritional education, Food advertising, Public policy.

Ana Lydia Sawaya é professora titular livre-docente da disciplina de Fisiologia da Nutrição, Departamento de Fisiologia, da Universidade Federal de São Paulo, e presidente do Comitê Cientifico do Centro de Recuperação e Educação Nutricional (CREN). @ - alsawaya@unifesp.br / https://orcid.org/0000-0002-2580-9557

Anna Maria Peliano é coordenadora do grupo de "Nutrição e Pobreza" do Instituto de Estudos Avançados da USP e pesquisadora do Instituto de Pesquisa Econômica (IPEA). @ - anna.peliano@ipea.gov.br / https://orcid.org/0000-0003-2254-3703

Maria Paula de Albuquerque é pediatra nutróloga e diretora clínica do Centro de Recuperação e Educação Nutricional (CREN). @ - saude_vm@cren.org.br / https://orcid.org/0000-0003-2111-4026

Semíramis Martins Álvares Domene é professora associada livre-docente do Departamento de Políticas Públicas e Saúde Coletiva da Universidade Federal de São Paulo. @ - semiramis.domene@unifesp.br / https://orcid.org/0000-0003-3003-2153

${ }^{\text {I }}$ Escola Paulista de Medicina, Universidade Federal de São Paulo, São Paulo, Brasil.

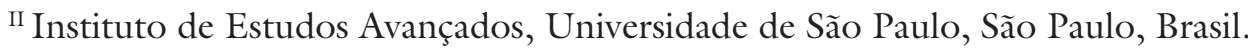

III Centro de Recuperação e Educação Nutricional, São Paulo, São Paulo, Brasil.

Iv Instituto Saúde e Sociedade, Universidade Federal de São Paulo, São Paulo, Brasil.

Recebido em. 20.8.2019 e aceito em 16.9.2019. 